\title{
KEEFEKTIFAN MODEL PEMBELAJARAN \\ DALAM MENINGKATKAN HASIL BELAJAR GEOGRAFI DITINJAU DARI KETERPAAN MEDIA ELEKTRONIK SISWA SMA
}

Stefania Octaviana Meo ${ }^{1} *$, Muhsinatun Siasah Masruri ${ }^{1}$

${ }^{1}$ Universitas Negeri Yogyakarta

${ }^{1}$ Jl. Colombo No. 1, Depok, Sleman 55281, Yogyakarta, Indonesia

* Corresponding Author. Email: nonnyarry@ gmail.com

\begin{abstract}
Abstrak
Penelitian ini bertujuan untuk membandingkan keefektifan antara model Discovery Learning dan model Problem-Based Learning dalam meningkatkan hasil belajar geografi peserta didik, ditinjau dari keterpaan media elektronik, serta mengetahui interaksi pengaruh antara model pembelajaran dan keterpaan media elektronik terhadap hasil belajar geografi.Penelitian ini merupakan penelitian kuasi eksperimen. Analisis data dilakukan menggunakan analisis deskripsi dan inferensial. Hasil penelitian ini adalah: (1) Model Discovery Learning lebih efektif jika dibandingkan dengan model Problem-Based Learning dengan nilai rata-rata72> 63 dan tarafsignifikan 0.00. (2) Hasil belajar dengan keterpaan media elektonik tinggi lebih baik daripada hasil belajar dengan ketepaan media elektronik rendah, nilai rata-rata $71.99>65$ dengan tarafsignifikan 0,00. (3) Hasil belajar peserta didik dengan keterpaan media massa elektronik tinggi pada model Discovery Learning lebih baik dari pada model Problem-Based Learningnilai rata-rata $77.59>63$ dengan tarafsignifikan 0,00. (4) Hasil belajar peserta didik dengan keterpaan media massa elektronik rendah pada model Discovery Learning lebih baik dari pada model Proble-Based Learningnilai rata-rata $67.59>62.77$ dengan taraf signifikan 0,00. (5) Model Discovery Learning lebih efektif dari pada model Problem-Based Learning jika dilihat dari keterpaan media elektronik tinggi dan rendah.
\end{abstract}

Kata kunci: discovery learning,problem- based learning, media elektronik

\section{THE EFFECTIVENESS OF TEACHING MODEL IN IMPROVING GEOGRAPHY LEARNING OUTCOMES BASED ON ELECTRONIC MEDIA EXPOSURE AT HIG SCHOOL}

\begin{abstract}
This study aims to compare the effectiveness between the Discovery Learning model and the model of Problem-Based Learning to improving the geography learning outcomes, based on electronic media exposure, and analyzing the interaction effect between models of learning and electronic media exposure on the outcomes of the geography learning. This study was a quasiexperimental. Data analysis was performed using descriptive analysis and inferential.The experiment data, was analized by Anava, and the result of this research are: (1) Discovery Learning is more effective than model of Problem-Based Learning (72> 62 and significance 0.00); (2) Learning outcames of student with high electroncc media exposure is more than the outcames of student with low electronic media exposure (71.99 > 65 and significance 0.00); (3) The Learning outcame of students with high electrinic media exposure in Discovery Learning model is more than the learning outcame of students Problem -Based Learning model (77.59>63 and significance 0.00); (iv) Learning outcame of students with low electrinic media exposure in Discovery Learning model is more than the learning outcame of students Proble-Based Learning model (67.59> 62.77and significance 0.00; (5) From the perspectiveof the both of the high and low electronic media exposure, the model Discovery Learning model is more effective than the Problem-Based Learning.
\end{abstract} Keywords: Effectiveness, learning model, electronic media exposure. 


\section{Pendahuluan}

Perubahan merupakan sesuatu yang harus terjadi di segala bidang, tidak terkecuali pada bidang pendidikan.Peningkatan kualitas pendidikan nasional dilakukan oleh pemerintah melalui pengembangan dan penyempurnaan kurikulum, pengembangan materi pembelajaran,perbaikan sistem evaluasi, pengadaan buku dan alat-alat pembelajaran, perbaikan sarana dan prasarana pendidikan, peningkatan kompetensi guru, serta peningkatan mutu pimpinan sekolah (Depdiknas, 2001, p. 3). Peningkatan kualitas pendidikan tersebut belum menunjukkan hasil sebagaimana yang diharapkan. Kualitas pendidikan dipengaruhi beberapa faktor, seperti: guru, siswa, pengelola sekolah (Kepala Sekolah, karyawan dan Dewan/Komite Sekolah), lingkungan (orangtua, masyarakat, sekolah), kualitas pembelajaran, dan kurikulum (Suhartoyo, 2005,p. 2).

Peraturan Menteri Pendidikan dan Kebudayaan Nomor 65 Tahun 2013 (Mendikbud, 1023) tentang standar proses pendidikan menyebutkan bahwa: Setiap pendidik pada satuan pendidikan berkewajiban menyusun Rencana Pelaksanaan Pembelajaran (RPP) secara lengkap dan sistematis agar pembelajaran dapat berlangsung secara interaktif, inspiratif, menyenangkan, menantang, memotivasi peserta didik untuk berpartisipasi aktif, serta memberi ruang yang cukup bagi kreativitas dan kemandirian sesi bakat, minat dan perkembangan fisik serta psikologis peserta didik.

Proses pembelajaran pada kurikulum 2013 untuk semua jenjang dilaksanakan dengan menggunakan pendekatan saintifik (scientific approach). Pendekatan saintifik merupakan pembelajaran yang berpusat pada peserta didik.

Berdasarkan hasil wawancara dengan beberapa peserta didik di SMA Negeri I dan SMA Negeri I Golewa, mereka dituntut untuk menguasai semua materi pelajaran sebanyakbanyaknya sehingga siswa menjadi terbebani untuk menguasai pelajaran yang dianggapnya tidak menyenangkan. Pelajaran geografi juga dapat membuat peserta didik terbebani karena merupakan pelajaran yang sarat materi. Peserta didik menuntut kemudahan dalam belajar, rasa aman dan cepat dalam memahami dengan suasana yang menyenangkan yang tidak menegangkan. Guru harus pandai memilih pendekatan yang dapat menimbulkan semangat bel- ajar peserta didik, antara lain menggunakan pendekatan saintifik. Trianto $(2009$, p. 22) mengemukakan bahwa: Model pembelajaran adalah suatu perencanaan atau suatu pola yang digunakan sebagai pedoman dalam merencanakan pembelajaran di kelas atau pembelajaran dalam tutorial dan untuk menentukan perangkat-perangkat pembelajaran termasuk di dalamnya buku-buku, film, komputer, kurikulum, dan lain-lain.

Kabupaten Ngada Provinsi Nusa Tenggara Timur(NTT) dipilih sebagai tempat penelitian karena berdasarkan pengamatan yang telah dilakukan, guru sering menggunakan metode ceramah dalam proses pembelajaran. Strategi yang digunakan tidak bervariasi dan kurang menarik.Tidak terdapat banyak interaksi antara pendidik dan peserta didik. Pendidik terbiasa menggunakan media cetak (modul, buku pelajaran dan LKS) dalam proses pembelajaran. Peserta didik menganggap mata pelajaran geografi sebagai mata pelajaran hafalan namun sulit diingat karena materinya yang begitu banyak.

Model pembelajaran yang mudah dilakukan dan belum pernah dilakukan di Kabupaten Ngada antara lain adalah model Pembelajaran Penemuan (Discovery Learning) dan Pembelajaran Berbasis Masalah (Problem Based Learning). Pembelajaran Discovery Learning adalah suatu model cara belajar siswa aktif untuk menemukan sendiri segala sesuatu yang menjadi tujuan pembelajaran sehingga hasil yang diperoleh dapat dipahami oleh siswa. Model problem based learning adalah model pembelajaran yang menggunakan siswa pada masalah-masalah nyata sehingga siswa dapat menggunakan caranya sendiri dalam mengembangkan keterampilan yang lebih tinggi dan mandiri (Hosnan, 2014, p. 296).

Pembelajaran merupakan suatu proses interaksi antara guru, peserta didik dan sumber belajar. Pemanfaatan internet sebagai media pembelajaran mengkondisikan peserta didik untuk belajar secara mandiri. Internet merupakan perpustakaan online yang di dalamnya terdapat banyak informasi yang dapat digunakan dalam pembelajaran. Peserta didik dapat menggunakan internet untuk memperoleh informasi yang dapat mendukung hasil belajar. Media pembelajaran harus menarik,dan dapat membuat siswa interaktif ,agar siswa dapat belajar secara menyenangkan sehingga membentuk suasana belajar yang nyaman dan kondusif; 
untuk itu diperlukan multimedia interaktif dalam proses pembelajaran di kelas (Candra, 2015, p 110).

Seiring dengan perkembangan jaman, di Kabupaten Ngada Provinsi Nusa Tenggara Timur, setiap sekolah memiliki fasilitas media eletronik yang berupa komputer dan internet yang dapat digunakan sebagai salah satu sumber informasi. Kenyataanya fasilitas yang telah disiapkan ini tidak dimanfaatkan oleh sekolah untuk membantu peserta didik dalam memperoleh informasi dalam pembelajaran.

Rumusan masalah dalam penelitian ini adalah: (1) apakah terdapat perbedaan hasil belajar geografi antara peserta didik yang mengikuti pembelajaran geografi dengan model Discovery Learningdan Problem Based Learning? (2). apakah terdapat perbedaan hasil belajar geografi antara peserta didik dengan keterpaan media massa elektronik tinggi dan peserta didik dengan keterpaan media massa elektronik rendah?; (3) apakah terdapat perbedaan hasil belajar geografi pada peserta didik dengan keterpaan media massa tinggi pada pembelajaran geografi dengan model Discovery Learning dan Problem Based Learning (4). Apakah terdapat perbedaan hasil belajar belajar pada peserta didik dengan keterpaan media massa rendah pada geografi dengan model Discovery Learning dan Problem Based Learning? (5) apakah model Discovery Learning lebih efektif dari pada model Problem Based Learning jika dilihat dari keterpaan media elektronik tinggi dan rendah ?

Sesuai dengan rumusan masalah adapun yang menjadi tujuan penelitian ini adalah: (1) perbedaan hasil belajar geografi antara peserta didik yang mengikuti pembelajaran geografi dengan model Discovery Learning dan Problem Based Learning; (2) perbedaan hasil belajar geografi antara peserta didik dengan keterpaan media massa elektronik tinggi dan keterpaan media massa elektronik rendah; (3) terdapat perbedaan hasil belajar geografi pada peserta didik dengan keterpaan media massa tinggi pada pembelajaran geografi dengan model Discovery Learing dan Problem Based Learning, (4) terdapat perbedaan hasil belajar belajar pada peserta didik dengan keterpaan media massa rendah pada geografi dengan model Discovery Learing dan Problem Based Learning, (5) Model Discovery Learning lebih efektif dari pada model Problem
Based Learning jika dilihat dari keterpaan media elektronik tinggi dan rendah.

Metode saintifik memiliki karakteristik doing science. Metode ini memudahkan guru atau pengembang kurikulum untuk memperbaiki proses pembelajaran, yaitu dengan memecah proses ke dalam langkah-langkah atau tahapan-tahapan secara terperinci yang memuat instruksi untuk siswa melaksanakan kegiatan pembelajaran. Hal inilah yang menjadi dasar dari pengembangan Kurikulum 2013 di Indonesia.

Motode saintifik sangat relevan dengan tiga teori belajar, yaitu Teori Bruner, Teori Piaget, dan Teori Vygotsky. Teori belajar Bruner disebut teori belajar penemuan. Peserta didik dapat memperoleh kepuasan intelektual dengan melakukan penemuan. Teori Piaget mengatakan bahwa belajar berkaitan dengan pembentukan dan perkembangan skema. Vigotsky dalam teorinya menyatakan bahwa pembelajaran terjadi apabila peserta didik belajar menangani tugas-tugas yang belum dipelajari namun tugas-tugas itu masih ada dalam jangkauan kemampuan peserta didik (Hosnan, 2014, p. 35).

Penerapan pendekatan saintifik dalam pembelajaran melibatkan keterampilan proses seperti mengamati, mengklasifikasi, mengukur, meramalkan, menjelaskan, dan menyimpulkan. Proses tersebut membutuhkan bantuan guru, akan tetapi bantuan guru tersebut harus semakin berkurang dengan semakin bertambah dewasanya siswa atau semakin tinggi kelasnya. Kurikulum 2013 menekankan pada pembelajaran, yaitu menggunakan pendekatan ilmiah. Kemendikbud (2013, p.9) menyatakan bahwa pendekatan ilmiah (scientific approach) adalah yang mendorong anak untuk melakukan keterampilan-keterampilan ilmiah seperti mengamati, menanya, mengumpulkan informasi, mengorganisasi, dan mengkomunikasikan.

Guru dapat mengunakan model-model pembelajaran yang tepat dengan pendekatan saintifik dalam proses pembelajaran agar pembelajaran menjadi lebih bermakna. Ridwan (2014, p. 88) mengatakan ada 4 model pembelajaran yang menggunakan pendekatan saintifik yaitu: pembelajaran berbasis Inquiri, Discovery Learning, Problem Based Learning, dan Project Based Learning.

Penelitian akan dilakukan pada SMA di Kabupaten Ngada Provinsi Nusa Tenggara Timur, mengunakan model Discovery Learn- 
ing dan Problem Based Learning. Peneliti menggunakan kedua model ini karena selain dapat meningkatkan dan membangun kreativitas peserta didik dalam mencari dan membahas permasalahan tentang pembelajaran, model pembelajaran ini belum pernah digunakan di sekolah yang akan diteliti.

Efektivitas secara umum dapat memperlihatkan sampai seberapa jauh suatu tujuan yang terlebih dahulu dapat ditentukan. Hal tersebut sesuai dengan pengertian efektivitas menurut Moore. D Kennet yang menjelaskan bahwa efektivitas adalah suatu ukuran yang menyatakan seberapa jauh target (kuantitas, kualitas, dan waktu) telah tercapai, atau makin besar target yang dicapai, dan makin tinggi efektivitasnya (Sumantri, 2015, p.1)

Keefektifan pembelajaran dapat memperlihatkan perbedaan yang nyata pada peserta didik setelahmengikuti proses pembelajaran dalam waktu yang relatif singkat, prestasi peserta didik meningkat, menunjukan sikap positif, dan peserta didik termotovasi untuk belajar. Menurut Jacobsen, Eggen, \& Kauchak (1989, p. 213) effective Instruction is devoted to these variables and the authors conclude that if a teacher is successful in immplenting one or more of these processes, there should be noticeable differences in students whithin a relatively short periode of time. Such differences include increased achievement, more positive attitudes, and greater interest in motivation for learning.

Kefektifan dapat menjawab seberapa jauh siswa dapat mencapai sasaran belajar yang telah ditentukan tiap-tiap unit. "Pengukuran keefekifan dapat dipastikan dari nilai ujian, nilai proyek dan kinerja, dan catatan dari pengamatan mengenai tingkah laku peserta didik" Kemp (1985, p. 20).

Model pembelajaran adalah prosedur yang sistematis tentang pola belajar untuk mencapai tujuan belajar serta sebagai pedoman bagi pengajar dalam merencanakan dan melaksanakan aktivitas pembelajaran. Model pembelajaran adalah kerangka konseptual yang melukiskan prosedur yang sistematis dalam mengorganisasikan pengalaman belajar untuk mencapai tujuan belajar tertentu dan berfungsi sebagai pedoman bagi pengajar dalam merencanakan dan melaksanakan aktivitas belajar. Joyce \& Weil (2000, pp. 6-7) berpendapat bahwa model of learning is the most important role of teacher to teach student how to learn as they: acquire information, ideas, skills, values, ways of thinking, means of expressing themselves"

Berdasarkan pendapat di atas model pembelajaran merupakan suatu rencana atau pola yang digunakan oleh guru untuk mengajarkan peserta didik untuk memperoleh informasi, ide, keterampilan, nilai-nilai, cara berpikir, sarana mengekspresikan diri dalam pembelajaran.

Pembelajaran berbasis masalah (PBL) didasarkan atas teori psikologi kognitif, terutama berlandaskan Teori Piaget dan Vigotsky (konstruktivisme). Menurut teori konstruktivisme, peserta didik belajar mengkonstruksi pe-ngetahuan melalui interaksi dengan lingkungannya. Pembelajaran berbasis masalah dapat membuat peserta didik belajar melalui upaya penyelesaian permasalahan dunia nyata (real world problem). Model Problem Based Learning adalah model pembelajaran dengan pendekatan pembelajaran peserta didik pada masalah yang nyata sehingga peserta didik dapat menyusun pengetahuannya sendiri, meningkatkan pengetahuan, dan kepercayaan diri sendiri (Abbas, 2000, p.13). Gallagher \& Gallagher (2013, p.127) berpendapat bahwa Problem-based learning is a student-centered approach that supports the instructional demands of the reform standards. It is characterized as a teaching model consistent with the principles of constructivism, driven by stimulating, openended questions and collaborative learning.

Ada 5 tahap dalam pembelajaran PBL menurut Arend (2015, p.421), yaitu: (1) Orientasi peserta didik terhadap masalah, (2) mengorganisasi peserta didik untuk belajar, (3) membimbing penyelidikan individual dan kelompok, (4) mengembangkan danmenyajikan hasil karya, (5) menganalisis dan mengevaluasi proses pemecahan masalah.

Discovery Learning adalah teori belajar yang didefinisikan sebagai proses pembelajaran yang terjadi bila peserta didik tidak disajikan dengan pelajaran dalam bentuk finalnya tetapi peserta didik mengorganisasi sendiri pelajaran tersebut. Bruner (1961, p. 31) berpendapat bahwa Discovery learning is a technique of inquiry-based learning and is considered a constructivist based approach to education. Practice in discovering for oneself teaches one to acquire information in a way that makes that information more readily viable in problem solving. 
Pengertian Discovery Learning menurut Jerome Bruner adalah metode belajar yang mendorong peserta didik untuk mengajukan pertanyaan dan menarik kesimpulan dari prinsip-prinsip umum praktis contoh pengalaman. Hal ini yang menjadi dasar dari ide J. Bruner ialah pendapat dari Piaget yang menyatakan bahwa anak harus berperan secara aktif dalam belajar di kelas. J.Bruner memakai cara dengan apa yang disebutnya Discovery learning, yaitu peserta didik mengumpulkan bahan yang dipelajari dengan suatu bentuk akhir (Hosan 2014, p. 281).

Model pembelajaran Discovery Learning merupakan teknik pembelajaran berbasis penyelidikan dan dianggap pendekatan berbasis konstruktivis untuk pendidikan. Model pembelajaran Discovery Learning mengajarkan peserta didik untuk memperoleh informasi dengan memperoleh informasi lebih mudah layak dalam pemecahan masalah.

Model pembelajaran ini menekankan pada ditemukannya konsep atau prinsip yang sebelumnya tidak diketahui. Guru berperan sebagai pembimbing dengan memberikan kesempatan kepada peserta didik untuk belajar secara aktif. Bahan ajar tidak disajikan dalam bentuk akhir tetapi peserta didik dituntut untuk melakukan serangkaian kegiatan mulai dari mengumpulkan informasi sampai dengan membuat kesimpulan dari materi yang disajikan. Guru dituntut untuk lebih kreatif menciptakan situasi yang dapat membuat peserta didik belajar aktif menemukan pengetahuannya sendiri. Metode belajar ini sesuai dengan Teori J. Bruner yang menyarankan agar peserta didik belajar secara aktif untuk menyusun konsep dan prinsip.

Ada 4 tahap dalam pembelajaran penemuan menurut Jacobsen, Eggen, \& Kauchak, (2012, p. 137) yaitu: (1) pengenalan. (2) pembuka dan penutup, (3) konvergen, (4) penutup dan Aplikasi.

Hasil belajar menurut Gagne dan Briggs (Suprihatiningrum, 2013, p.37) adalah kemampuan-kemampuan yang dimiliki oleh peserta didik sebagai akibat perbuatan belajar dan dapat diamati melalui penampilan siswa (learner's performance)

Proses pembelajaran dikatakan berhasil apabila indikator pencapaian hasil belajar dapat tercapai. Pemberian indikator dalam pembelajaran mengacu pada hasil belajar siswa yang harus dikuasai siswa. Sesuai dengan tak- sonomi tujuan pembelajaran, hasil belajar dibedakan dalam tiga aspek, yaitu hasil belajar aspek kognitif, afektif, dan psikomotorik (Suprihatiningrum, 2013, pp.38-47).

Internet, atau International Networking didefenisiskan dua komputer atau lebih yang memiliki konektivitas membentuk jaringan komputer hingga meliputi jutaan komputer. Menurut Rusman (2013, p.49) internet merupakan jaringan yang luas dari jutaan jaringan komputer yang menjangkau jutaan orang di seluruh dunia. Jaringan internet juga didefenisikan sebagai jaringan komputer yang mampu menghubungkan komputer di seluruh dunia, sehingga berbagai jenis dan bentuk informasi dapat dikomunikasikan antarbelahan dunia secara instan dan global (www.jurnalkopertis4.org).

Perkembangan teknologi yang disebut internet memberikan pengaruh yang demikian besar bagi masyarakat untuk memperoleh informasi yang dibutuhkan. Manfaat internet menurut Hardjito (Rusman 2013, p.52), yaitu Manfaat internet lebih banyak disebabkan oleh kecepatan, kemudahan, murah, dan canggih. Bila saat ini berbicara internet, pemakai lebih cenderung menggunakannya untuk kebutuhan e-mail dan browsing padahal kemampuan dan fasilitas dari internet adalah lebih dari itu, transfer pengetahuan yang dimungkinkan melalui internet justru bisa jauh lebih efektif sekaligus efisien untuk membentuk intelektual manusia muda dan masa depan".

Pemanfaatan internet dalam pembelajaran mengkondisikan para peserta didik untuk belajar mandiri. " Through independent study, students become doers, as well as thinkers" (Rusman, 2014, p. 340). Para siswa dapat mengakses secara online dari berbagai perpustakaan, museum, data base dan dapat memperoleh sejumlah informasi tentang berbagai peristiwa. Pemanfaatan internet ini, siswa dapat berperan sebagai seorang peneliti, menjadi seorang analisis, tidak hanya konsumen informasi saja.

\section{METODE PENELITIAN}

Penelitian ini menggunakan metode eksperimental semu (quasi-experimental research). Hal ini dikarenakan peneliti tidak memungkinkan untuk mengendalikan dan memanipulasi semua variabel yang relevan. Penelitian menggunakan 2 kelompok eksperimen 
yaitu Discovery Learning dan Problem Based Learning yang di lihat dari keterpaan media elektronik.

Penelitian quasi eksperimen ini menggunakan factorial desain 2x2 untuk membandingkan dua model pembelajaran PBL dan DL pada siswa SMA Negeri I Bajawa dan SMA Negeri I Golewa.

Tabel 1. Desain Penelitian

\begin{tabular}{|c|c|c|c|}
\hline $\begin{array}{l}\text { Keterpa } \\
\text { Massa e }\end{array}$ & DL & PBL & Total \\
\hline Tinggi & A & B & $\mathrm{AB}$ \\
\hline Rendah & $\mathrm{C}$ & D & CD \\
\hline
\end{tabular}

Keterangan:

A : Kelompok peserta didik yang mengikuti model Discovery Learning.

B : Kelompok peserta didik yang mengikuti model Problem Based Learning.

$\mathrm{AB} \quad$ : Kelompok peserta didik yang mengikuti model Discovery Learning dan Problem Based Learning dengan tingkat keterpaan media massa elektronik tinggi.

CD : Kelompok peserta didik yang mengikuti model Discovery Learning dan Problem Based Learning dengan tingkat keterpaan media massa elektronik rendah

$\mathrm{A}+\mathrm{C}:$ Kelompok peserta didik yang mengikuti model Discovery Learningdilihat dari keterpaan media elektronik tinggi dan rendah

B+D : Kelompok peserta didik yang mengikuti model Problem Based Learning dilihat dari keterpaan media elektronik tinggi dan rendah

Tempat Penelitian ini dilakukan di SMA Negeri I Bajawa dan SMA Negeri I Golewa Kabupaten Ngada Provinsi Nusa Tenggara Timur. Penelitian dilaksanakan pada semester genap tahun ajaran 2015/2016.

Pengambilan sampel dilakukan dengan cara random sampling. Sugiyono (2004, p. 7) berpendapat bahwa random sampling adalah pengambilan sampel yang dilakukan secara random terhadap unit-unit atau sub-sub populasi. Populasi dari sampel random sampling ini adalah seluruh siswa kelas XI semester II SMA Negeri di Kabupaten Ngada tahun ajaran 2015/2016.

Teknik pengumpulan data digunakan dengan cara: (1) Dokumentasi dilakukan untuk mengambil data primer berupa nilai UTS pada mata pelajaran geografi. Nilai UTS digunakan untuk mengetahui nilai rata-rata setiap kelas dan perbandingan antara kedua model, (2) Tes berupa pertanyaan-pertanyaan dalam bentuk pilihan ganda dengan lima pilihan jawaban pada mata pelajaran geografi kelas XI IPS SMAN I Bajawa dan XI IPS SMAN I Golewa. Standar kompetensi (SK) 3.2 Menganalisis Pemanfaatan dan Pelestarian Lingkungan Hidup sebanyak 30 soal, (3) Nontes (Angket) digunakan untuk mengumpulkan data tentang keterpaan media elektronik. Angket diberikan di awal pertemuan dengan tujuan untuk mengetahui gaya belajar siswa. Angket gaya belajar berisikan 20 soal pertanyaan.

Analisis data pada bagian ini bertujuan untuk mengkaji kebenaran hipotesis yang diajukan. Analisis data dalam penelitian ini dengan menggunakan analisis varian dua jalur. Dasar pemikiran teknik ini adalah menguji perbedaan variansi total dalam suatu eksperimen yang dapat dianalisis menjadi dua sumber varian antarkelompok dan varian antarkelompok. Anava dua jalur dapat digunakan untuk menguji perbedaan dua mean atau lebih.

Uji prasyarat parametrik dilakukan terlebih dahulu sebelum analisis data dilakukan. Uji parametrik terdiri dari uji normalitas dan uji homogenitas. Data hasil penelitian dianalisis dengan menggunakan statistik deskriptif untuk mengetahui penggunan media eletronik dalam belajar dan hasil belajar geografi. Pengujian hipotesis menggunakan anava dua jalur dan data hasil penelitian ini akan diolah dengan menggunakan program SSPSS for windows versi 19.

\section{Hasil Penelitian dan Pembahasan}

Penelitian ini menggunakan model belajar Discovery Learning yang merupakan teknik pembelajaran berbasis penyelidikan dan berbasis konstruktivis untuk pendidikan. Model pembelajaran Discovery Learning mengajarkan peserta didik untuk memperoleh infor- 
masi agar lebih mudah dalam memecahkan masalah.

Wicox (Hosnan 2014, p. 281), dalam pembelajaran penemuan (Discovery Learning), siswa didorong untuk belajar,dengan terlibat aktif dengan konsep prinsip mereka sendiri. Guru diharapkan dapat mendorong peserta didik agar memiliki pengalaman dan melakukan percobaan yang memungkinkan mereka menemukan ide-ide bagi diri mereka sendiri.

Hasil penelitian ini membuktikan bahwa hasil belajar antara peserta didik yang mengikuti pembelajaran geografi dengan model Discovery Learning lebih baik dari pada peserta didik yang mengikuti pembelajaran dengan model Problem-Based Learning dengan nilai signifikansi lebih kecil dari $0,05(\mathrm{p}=$ $0.00<0,05$.

Tabel 2. Hasil Belajar Terhadap Model Belajar

\begin{tabular}{|c|c|c|c|c|c|c|}
\hline Model & $\begin{array}{l}\text { Perla- } \\
\text { kuan }\end{array}$ & Mean & $\mathrm{n}$ & $\mathrm{T}$ & Sig & Ket \\
\hline \multirow[t]{2}{*}{ Belajar } & $D L$ & 72,84 & 34 & 4,510 & 0,000 & Sign \\
\hline & $P B L$ & 63,11 & 30 & 4,523 & 0,000 & Sign \\
\hline
\end{tabular}

Penelitian ini juga bertujuan untuk mengetahui hasil belajar peserta didik dilihat dari keterpan media tinggi dan rendah. Media elektronik khususnya internet memiliki ribuan informasi yang dapat diperoleh oleh peserta didik untuk meningkatkan hasil belajar. Hardjito (Rusman 2013, p. 52) mengatakan manfaat internet lebih banyak disebabkan oleh kecepatan, kemudahan, murah, dan canggih. Bila saat ini berbicara internet, pemakai lebih cenderung menggunakannya untuk kebutuhan $e$-mail dan browsing padahal kemampuan dan fasilitas dari internet adalah lebih dari itu. Transfer pengetahuan yang dimungkinkan melalui internet justru bisa jauh lebih efektif sekaligus efisien untuk membentuk intelektual manusia muda dan masa depan.

Hasil penelitian membuktikan bahwa hasil belajar dengan keterpaan media elektronik tinggi memilki rata-rata (71) dengan nilai signifikan $(0,004)$ dan hasil belajar dengan keterpaan media elektronik rendah memiliki ratarata $(65,00)$ dengan nilai signifikan $(0,005)$.
Tabel 3. Hasil Belajar Terhadap Keterpaan Media Elektronik

\begin{tabular}{llllll}
\hline \multirow{2}{*}{$\begin{array}{l}\text { Hasil } \\
\text { Belajar }\end{array}$} & Perlakuan & N & Mean & Sig & Ket \\
\cline { 2 - 6 } & Elektonaan Media & 30 & 71.99 & 0,004 & Sign \\
\cline { 2 - 6 } & $\begin{array}{l}\text { Keterpaan Media } \\
\text { ElektonikRendah }\end{array}$ & 34 & 65,00 & 0,005 & Sign \\
\hline
\end{tabular}

Penelitian ini membuktikan bahwa hasil belajar model belajar Discoveri Learning dengan keterpaan media eletronik tinggi lebih baik dibanding Problem Based learning. Hasil analilis perhitungan menunjukan hasil belajar dengan keterpaan media eletronik tinggi pada model Discovery Learning memiliki nilai ratarata $(77,5)$ dengan nilai signifikan $(0,000)$ dan hasil belajar Problem Based Learning memiliki nilai rata-rata $(63,6)$ dengan nilai signifikan $(0,000)$. Adanya perbedaan hasil belajar yang benar-benar nyata pada kedua model belajar ini membuktikan bahwa model Discoveri Learning dengan keterpaan media elektronik tinggi lebih baik dari model Problem based learning.

Tabel 4. Hasil Belajar Terhadap Model Belajar Pada Keterpaan Media Elektronik Tinggi

\begin{tabular}{lcccc}
\hline Hasil Belajar & Perlakuan & N & Mean & Sig \\
\cline { 2 - 5 } Dengan & DL & 18 & 77,59 & 0,00 \\
\cline { 2 - 5 } $\begin{array}{l}\text { Keterpaan } \\
\text { Media Tinggi }\end{array}$ & PBL & 12 & 63,61 & 0,00 \\
\hline
\end{tabular}

Peneliti juga ingin membuktikan bahwa hasil belajar peserta didik dengan keterpaan media massa elektronik rendah pada pembelajaran geografi dengan model Discovery Learning lebih tinggi dari pembelajaran Problem-Based Learning. Hasil penelitian membuktikan bahwa hasil belajar pada model Discovery Learing dengan keterpaan media rendah memiliki nilai rata-rata $(67,5)$ dengan nilai signifikan $(0,074)$ dan model Problem Based Learning memiliki nilai rata-rata $(62,77)$ dengan nilai signifikan $(0,072)$. Hal ini membuktikan bahwa pada penelitian ini model Discovery Learning lebih baik dari model Problem-Based Learning. Model Discovery Learning dengan keterpaan media eletronik yang tinggi dan rendah memiliki nilai rata-rata yang lebih tinggi jika dibandingkan dengan model Proble-Based Learning. Ini membuktikan bahwa peserta didik dengan model Discovery learning dapat meningkatkan hasil belajar, ke- 
terampilan-keterampilan dan proses-proses kognitif yang dapat mengarahkan kegiatan belajarnya sendiri dengan melibatkan akalnya

Tabel 5. Hasil Belajar Terhadap Model Belajar Pada Keterpaan Media Elektronik Rendah

\begin{tabular}{lccccc}
\hline Hasil Belajar & Perlakuan & N & Mean & Sig & Ket \\
\cline { 2 - 6 } $\begin{array}{l}\text { DenganKeter } \\
\text { paan Media }\end{array}$ & DL & 16 & 65.59 & 0,074 & Sign \\
\cline { 2 - 6 } Rendah & PBL & 18 & 62.77 & 0,072 & Sign \\
& & & & &
\end{tabular}

Penelitian ini bertujuan untuk mengetahui bahwa model Discovery Learning lebih efektif dari pada model Problem Based Learning jika dilihat dari keterpaan media elektronik tinggi dan rendah. Hasil penelitian ini juga membuktikan bahwa dengan model Discovery Learning peserta didik memiliki hasil belajar yang lebih tinggi baik keterpaan media elektronik tinggi maupun rendah

Hasil uji anava 2 faktor untuk variabel dengan model pembelajaran dan media elektronik terhadap hasil belajar dinyatakan signifikan apabila nilai $\mathrm{p}<0,005$ dan $\mathrm{F}$ hitung $>$ $\mathrm{F}$ tabel. Artinya, memang ada perbedaan hasil belajar dengan model belajar dan keterpaan media.

Tabel 6. Interaksi Model Pembelajaran dan Media Elektronik Terhadap Hasil Belajar

\begin{tabular}{lccccc}
\hline Source & $\begin{array}{c}\text { Type III } \\
\text { Sum of } \\
\text { Squares }\end{array}$ & Df & $\begin{array}{c}\text { Mean } \\
\text { Square }\end{array}$ & F & Sig. \\
\hline Corrected Model & $2376,687^{\mathrm{a}}$ & 3 & 792,229 & 12,732 &, 000 \\
\hline Intercept & 286843,860 & 1 & 286843,86 & 4610,008 &, 000 \\
\hline Metode & 1361,208 & 1 & 1361,208 & 21,877 &, 000 \\
\hline Media & 464,419 & 1 & 464,419 & 7,464 &, 008 \\
\hline Metode * Media & 333,595 & 1 & 333,595 & 5,361 &, 024 \\
\hline Error & 3733,319 & 60 & 62,222 & & \\
\hline Total & 304501,800 & 64 & & & \\
\hline Corrected Total & 6110,007 & 63 & & & \\
\hline
\end{tabular}

Berdasarkan hasil uji anava dua faktor untuk model belajar terhadap hasil belajar diperoleh $\mathrm{F}=21,877$ dengan nilai signifikan 0,000 . Keterpaan media elektronik terhadap hasil belajar diperoleh $\mathrm{F}=7,464$ dan $\alpha=0.008$. Model Pembelajaran dan Keterpaan media elektronik terhadap hasil belajar diperoleh $\mathrm{F}=$ 5,361 dan $\alpha=0,024$. Ini berarti terdapat perbedaan yang nyata antara hasil belajar dengan model pembelajaran dan keterpaan media elektronik yang dapat mempengaruhi hasil belajar geografi peserta didik.

Tabel 7. Rangkuman Hasil Anava Dua Jalur

\begin{tabular}{ccc} 
Keterpaan Media $_{\text {Mektronik }}$ & DL & PBL \\
\hline Tinggi & & \\
\hline Rendah & 67,50 & 63,61 \\
\hline
\end{tabular}

Berdasarkan tabel rangkuman hasil uji anava dua jalur, membuktikan bahwa model Discovery Learning lebih efektif dibandingkan dengan Problem-Based Learning jika dilihat dari keterpaan media elektronik tinggi dan rendah. Hasil belajar peserta didik pada model Discovery Learning dengan keterpaan media eletronik tinggi maupun rendah lebih tinggi jika dibandingkan dengan model ProblemBased Learnig.

\section{SIMPULAN}

Berdasarkan hasil analisis dan pembahasan serta temuan-temuan yang diperoleh dalam penelitian ini, maka dapat disimpulkan beberapa hal sebagai berikut: (1) peserta didik yang mengikuti pembelajaran geografi dengan model belajar Discovery Learning memiliki hasil belajar yang lebih tinggi dari pada peserta didik yang mengikuti pembelajaran dengan model Problem Based Learning, (2) hasil belajar geografi peserta didik dengan keterpaan media massa elektronik tinggi lebih baik dari pada peserta didik dengan keterpaan media massa elektronik rendah, (3) hasil belajar peserta didik dengan keterpaan media massa elektronik tinggi pada pembelajaran geografi dengan model Discovery Learning lebih baik model Problem Based Learning, (4) hasil belajar peserta didik dengan keterpaan media massa elektronik rendah pada pembelajaran geografi dengan model Discovery Learning lebih baik model Problem Based Learning, (5) model Discovery Learning lebih efektif dari pada model Problem Based Learning jika dilihat dari keterpaan media elektronik tinggi dan rendah.

Mengacu pada hasil-hasil penelitian sebagaimana yang diungkapkan di atas, maka implikasi dari hasil-hasil tersebut diuraikan se- 
bagai berikut: (1). Penerapan model Discovery Learning dapat dijadikan sebagai alternatif sebagai model belajar dalam upaya meningkatkan hasil belajar geografi, (2) penerapan model Discovery Learning direspon dengan baik oleh peserta didik, sehingga dipandang berpotensi untuk mengubah cara pandang peserta didik bahwa belajar geografi bukan pelajaran hafalan materi tetapi memahami fenomena yang terjadi dalam kehidupan sehari-hari dengan belajar menemukan dari apa yang mereka alami dalam kehidupan sehari-hari, (3) penerapan model Discovery Learning yang dikelola dengan baik oleh guru, dapat memberikan nuansa pedagogik yang sangat kondusif khususnya bagi peserta didik yang memiliki kemampuan menengah dalam mengembangkan kemampuan dan nilai-nilai afektif, (4) penggunaan media elektronik sebagai sumber informasi dalam proses pembelajaran geografi dinilai mampu meningkatkan hasil belajar geografi peserta didik.

Berdasarkan kesimpulan dan implikasi di atas penelitian beberapa beberapa saran sebagai berikut: (1) penerapan model Discovery Learning dapat dijadikan sebagai alternatif dalam proses pembelajaran untuk meningkatkan hasil belajar peserta didik, (2) penggunakan model Problem Based Learning membutuhkan waktu yang cukup untuk melakukan persiapan sehingga dapat memperoleh hasil yang maksimal, (3) mengubah cara pandang peserta didik tentang model pembelajaran dimana mereka lebih peran dalam proses pembelajaran, sehingga peserta didik lebih mengingat apa yang telah dipelajari, (4) Guru dapat menggunakan media eletronik (internet) selama proses pembelajaran berlangsung guna meningkatkan hasil bejajar peserta didik

\section{Daftar Pustaka}

Abbas, N. (2000). Pengembangan perangkat pembelajaran Matematika berorientasi model pembelajaran berbasis masalah. Surabaya :

Program Studi Pendidikan

Matematika Pasca Sarjana-

Universitas Negeri Surabaya.

Arend, R. (2015). Learning To Taech (10th Ed.). New York: 2 Penn Plaza.

Bruner, J. (1961). The act of discovery. Harvard Educational Review, 31(1), 21-32.
Candra, A. (2015). Pengembangan Multimedia Interaktif dengan Pendekatan Saintifik untuk Pembelajaran Pkn SMP. Harmoni Sosial: Jurnal Pendidikan IPS Volume 2, No 2, September 2015 (109-114).

Eggnen, P. \& Kauchak, D. (2012). Strategies and Models for Teachers: Teaching Content and Thinking skills. Boston: Pearson

Gallagher, S. \& Gallagher, J. (2013). Using problembased learning to explore unseen academic potential. Interdisciplinary Journal of Problembased Learning, 7(1), http://dx.doi.org/10.7771/15415015.1322

Hosnan. (2014). Pendekatan Saintifik dan kontekstual dalam pembelajaran Abad 21. Bogor: Ghalia Indonesia.

http://www.kopertis4.or.id/organisasi/sambuta n-koordinator-kopertis-wilayah-iv/

Kemendikbud. (2013). Konsep Pendekatan Saintifik. Disajikan dalam Pelatihan Kurikulum 2013. IKIP PGRI Semarang, 30 Juli 2013

Jacobsen, D. A., Eggen, P., \& Kauchak, D. (1989). Method for Teaching: Promoting student learning in $K-12$ classroom. Paperback

Joyce, B., \& Weil, M (2000). Model of teaching. Amerika: A. Person Education Compani

Kemp, J. E. (1985). Designing and producing instrructional media. New York: Macmillan College publishing

Ridwan. (2004). Metode Riset. Jakarta: Rineka Cipta .

Mendikbud RI. Peraturan Menteri Pendidikan dan Kebudayaan Republik Indonesia Nomor 65 Tahun 2013 tentang Standar Proses Pendidikan Dasar dan Menengah (2013)

Rusman. (2013). Pembelajarn berbasis teknologi informasi dan komunikasi: mengembangkan profesionalisme Guru. Jakarta: Raja Grafindo Persada. 
Rusman. (2014). Model-model pembelajaran: mengembangkan profesionalisme guru. Jakarta: Raja Grafindo Persada.

Suhartoyo, E. (2005). Pengalaman Peningkatan Melalui Pengembangan Budaya Sekolah Di SMAN 1 Kasihan Bantul. Disajikan dalam Seminar Nasional Peningkatan Mutu Pendidikan Melalui Pengembangan Budaya Sekolah, tanggal 23 November di Universitas Negeri Yogyakarta.

Sugiyono. (2007). Metode penelitian pendidikan, pendekatan kuantitaif dan kualitatif. Bandung: AlfaBeta.
Sumantri, M. (2015). Strategi pembelajaran: teori praktik di tingkat pendidikan dasar. Jakarta: Raja Grafindo.

Suprihatiningrum, J. (2013). Strategi pembelajaran: teori dan aplikasi. Yogyakarta: Ar-Ruzz Media.

Trianto. (2009). Mendesain model pembelajaran inovatif-progresif: konsep, landasan, dan implementasinya pada kurikulum tingkat satuan pendidikan. Jakarta: Kencana Prenada Media Group. 